\title{
O que pensam os orientadores de estudo sobre o processo formativo proporcionado pelo Pacto Nacional pela Alfabetização na Idade Certa?
}

Cancionila Janzkovski Cardoso

André Luís Janzkovski Cardoso

\section{Resumo}

O objetivo deste texto é explorar as percepções dos orientadores de estudo , representantes das redes municipais e estadual de educação de 141 municípios do estado de Mato Grosso, Brasil, sobre contribuições, impactos e mudanças em suas práticas pedagógicas, após terem participado do Pacto Nacional pela Alfabetização na Idade Certa (Pnaic), de 2013 a 2015. A pesquisa ocorre na confluência de três importantes campos do conhecimento educacional: política educacional, formação de professores e alfabetização. Os dados foram obtidos de surveys realizadas anualmente, totalizando 809 respostas. Os resultados foram sistematizados em seis categorias que evidenciaram percepções favoráveis dos orientadores de estudo em relação à formação continuada de alfabetizadores, destacando aspectos concernentes a contribuições, impactos e mudanças nas práticas pedagógicas, aliados aos princípios formativos, aos objetivos e ao processo de formação continuada realizada pelo Pnaic.

Palavras-chave: formação continuada de professores; pacto social em educação; professor alfabetizador. 


\section{Abstract \\ What do study advisors think about the formation process the National Agreement for Literacy at the Right Age offers?}

This paper aims to explore the perception of study advisors, which are representatives of the municipal and state education networks from 141 municipalities from Mato Grosso, Brazil, on the contributions, impacts and changes on their own pedagogical practices upon their participation on the National Agreement for Literacy at the Right Age (PNAIC), from 2013 to 2015. The research is situated amidst three important educational fields: educational policy, teacher training and literacy. Data were raised from annual surveys with 809 answers. Results were systematized in six categories that revealed that study advisors' perceived positively the continued literacy-teachers training, emphasizing aspects regarding the contributions, impacts and changes in the pedagogical practices, in connection to PNAIC's formative principles, objectives and process of continuing education.

Keywords: continued teachers training; education social pact; literacy teacher.

\section{Resumen \\ ¿Qué piensan los orientadores de estudio sobre el proceso de formación proporcionado por el Pacto Nacional de Alfabetización en la Edad Correcta?}

El objetivo de este texto es explorar las percepciones de los orientadores de estudio, representantes de las redes municipales y estatal de educación de 141 municipios en el estado de Mato Grosso, Brasil, sobre contribuciones, impactos y cambios en sus prácticas pedagógicas, después de haber participado en el Pacto Nacional de Alfabetización en la Edad Correcta (Pacto Nacional pela Alfabetização na Idade Certa - Pnaic), de 2013 a 2015. La investigación se lleva a cabo en la confluencia de tres campos importantes del conocimiento educativo: política educativa, capacitación docente y alfabetización. Los datos se obtuvieron de encuestas realizadas anualmente, con un total de 809 respuestas. Los resultados se sistematizaron en seis categorías que mostraron percepciones favorables de los orientadores de estudio en relación con la educación continua de los alfabetizadores, señalando aspectos relacionados con las contribuciones, impactos y cambios en las prácticas pedagógicas, aliados a los principios de capacitación, los objetivos y el proceso de formación continua llevado a cabo por el Pnaic.

Palabras clave: formación continua de profesores; pacto social en educación; profesor alfabetizador. 


\section{Preâmbulo}

O objetivo deste texto é explorar as percepções dos orientadores de estudo (OE), representantes das redes municipais e estadual de educação de 141 municípios do estado de Mato Grosso, Brasil, sobre as contribuições, os impactos e as mudanças em suas práticas pedagógicas, após terem participado do Pacto Nacional pela Alfabetização na Idade Certa (Pnaic), de 2013 a 2015.

O Pnaic foi um programa de formação continuada presencial, destinado a professores alfabetizadores do Ministério da Educação (MEC), organizado em rede e coordenado nos estados pelas universidades públicas. Os OE representavam o perfil que se vinculava à universidade, eram oriundos dos 141 municípios do estado e tinham a tarefa de ministrar a formação aos professores alfabetizadores (PA). Segundo o MEC, os OE seriam "[...] escolhidos entre os próprios professores pertencentes ao quadro das redes de ensino e com experiência como tutores do Pró-Letramento. Trata-se de uma formação entre pares, da qual deriva a constituição de um aprendizado em rede [...]", e, além de ministrar o curso de formação e acompanhar a prática pedagógica dos professores alfabetizadores cursistas, teriam como atribuições "[...] avaliar sua frequência e participação, manter registro de atividades dos professores alfabetizadores cursistas [...] e apresentar relatórios pedagógicos e gerenciais das atividades referentes à formação dos professores alfabetizadores cursistas" (Brasil. MEC, 2012a, p. 25).

O tema desta pesquisa se encontra na confluência de três importantes campos do conhecimento em educação: política educacional, formação de professores e alfabetização.

\section{Política pública educacional, formação de professores e alfabetização}

Dispomos, atualmente, de referencial teórico-analítico que permite analisar a política educacional como um campo em permanente ebulição, que tem natureza complexa e controversa. Os pesquisadores ingleses Stephen Ball e Richard Bowe, divulgados no Brasil especialmente por Mainardes (2006, p. 96), caracterizaram o ciclo de política como processo contínuo, feito de disputas e embates, no qual "os profissionais que atuam nas escolas não são totalmente excluídos dos processos de formulação ou implementação de políticas". Os autores chamam a atenção para que a análise de políticas incida sobre "a formação do discurso da política e sobre a interpretação ativa que os profissionais que atuam no contexto da prática fazem para relacionar os textos da política às práticas".

Mainardes (2018), Ball e Bowe (1992) propuseram que o ciclo contínuo da política é constituído por três contextos inter-relacionados: o da influência, o da produção do texto e o da prática. No contexto da influência, as políticas públicas são elaboradas e os discursos políticos são construídos em meio a disputas de grupos e de finalidades da educação. O contexto da produção do texto se relaciona ao primeiro, 
ou seja, representa a política, mas procura se articular com uma linguagem de interesse do público geral, o que nem sempre resulta em textos claros e coerentes. São os textos oficiais e políticos, os comentários oficiais, os vídeos, os resultados de disputas e os acordos, por exemplo, que serão lidos no contexto da prática. O contexto da prática é "o lugar onde a política é sujeita à interpretação e recriação e onde produz efeitos e consequências que podem representar mudanças e transformações significativas na política original" (Mainardes, 2006, p. 98).

Em 1994, os autores reformularam a abordagem inicial, propondo o quarto contexto: o dos resultados/efeitos, descrito por Mainardes (2018, p. 4) como aquele que se preocupa com "questões de justiça, de igualdade e de liberdade individual"; e o quinto contexto: o da estratégia política, que "envolve a identificação de um conjunto de atividades sociais e políticas que seriam necessárias para lidar com as desigualdades criadas ou reproduzidas pela política investigada" e considerado essencial para a pesquisa social crítica.

Mainardes defende a necessidade de estudos que articulem os três contextos (desmembrados em cinco) com os efeitos e resultados, em especial os enunciados por aqueles que participaram da formulação, implantação e/ou reinterpretação de uma determinada política educacional.

Em relação à formação de professores, é preciso lembrar, inicialmente, que a profissão docente se consolidou com a escola moderna, que, apesar de naturalizada, tem gerado, há muitas décadas, sentimentos de insatisfação e mal-estar (Canário, 2005). Boa parte do que professores e professoras aprendem para atuar advém das culturas escolares, consolidadas em contextos, que exprimem:

[...] um conjunto de teorias, ideias, princípios, normas, modelos, rituais, inércias, hábitos e práticas (formas de fazer e pensar, mentalidades e comportamentos) sedimentadas ao longo do tempo em forma de tradições, regularidades e regras de jogo que se transmitem de geração em geração e geram estratégias de atuação. (Viñao, 2007, p. 87).

As culturas escolares estão associadas a crenças seculares fortemente enraizadas na profissão, que orientam a experiência da escola e são resistentes à mudança (Viñao, 2007). Assim, temos o paradoxo de uma profissão baseada, ainda, em práticas seculares e sedimentadas, frente a um mundo em transformação, que exige um perfil profissional altamente conectado com a nova situação.

Desse modo, o professor tem sido visto como o principal responsável pela qualidade do ensino, embora essa responsabilização não venha acompanhada de melhoria em suas condições de vida, trabalho e salário. Atuando em um mundo globalizado e em uma sociedade altamente excludente, como é a brasileira, são incontáveis os desafios encontrados pelos professores. Conforme Gatti, Barreto e André (2011, p. 25), "[...] a nova situação solicita, cada vez mais, que esse(a) profissional esteja preparado(a) para exercer uma prática contextualizada, atenta às especificidades do momento, à cultura local, ao alunado diverso em sua trajetória de vida e expectativas escolares". É necessário muito investimento em uma prática que articule conhecimentos e habilidades cognitivas referentes ao ato de ensinar, mas, também, postura ética, valores, atitudes, capacidade criadora e transformadora. 
Todas essas questões colocam desafios imensuráveis para as práticas e para as políticas de formação inicial e continuada.

Nóvoa (2009, p. 7) chamou a atenção para o "regresso dos professores ao centro das nossas preocupações e das nossas políticas". Segundo o autor, há uma espécie de consenso sobre princípios e medidas necessárias para assegurar a aprendizagem docente e o desenvolvimento profissional dos professores. O que pouco ou nada se encontra nessa "inflação retórica" é a voz dos professores. Nesse sentido, Nóvoa (2009, p. 12) defende a tese de que "é preciso passar a formação de professores para dentro da profissão".

Nessa direção, do professor no centro do debate, pesquisas como a de Gatti, Barreto e André (2011) evidenciam que a formação no Brasil tem ganhado lugar de destaque tanto nas políticas como na pesquisa, fazendo com que o campo se amplie e se fortaleça grandemente. Para essas autoras:

[...] o exame das políticas no âmbito em que elas são formuladas nos permitiu identificar muitos de seus pressupostos e direcionamentos, constatar sua diversidade e riqueza e, ainda, várias de suas fragilidades nos diferentes níveis de atuação das instâncias federadas. (Gatti; Barreto; André, 2011, p. 251).

Um conjunto de leis criadas no Brasil nas últimas três décadas aponta para o esforço que se fez no âmbito da formação de professores, com vistas à melhoria da qualidade educacional, notadamente as normas que estabelecem as diretrizes para a formação inicial e continuada dos profissionais da educação:

- Lei n 12.796, de 4 de abril de 2013 - a formação dos docentes para atuar na educação básica seria feita em nível superior;

- Resolução CNE/CP n 2, de $1^{\circ}$ de julho de $2015^{1}$ - estabelece as diretrizes para a formação inicial e continuada, tomando como princípios, entre outros, uma sólida formação teórica e interdisciplinar; a unidade teoriaprática; o trabalho interdisciplinar; o compromisso social e a valorização profissional;

- Lei no 11.738, de 16 de julho de 2013 - regula o piso salarial nacional dos profissionais do magistério público.

A formação continuada, definida em lei como direito e necessidade, lócus desta pesquisa, frente à realidade concreta dos sujeitos/professores, transita entre ideais, necessidades, limites e possibilidades. Tais aspectos gerais estão na base da docência, mas ainda há a particularidade do grau, da disciplina, ou campo do conhecimento em que o professor atua.

Por exemplo, a alfabetização tem sido um dos grandes desafios do projeto republicano de escola para o povo, que tem atravessado os tempos. Desde a

\footnotetext{
${ }^{1}$ A Resolução CNE/CP no 2, de $1^{\circ}$ de julho de 2015, representou um avanço para o campo, em especial por enfatizar a valorização dos profissionais e a importância da formação continuada. Foi revogada pela Resolução CNE/CP n 2, de 2019, que representa um retrocesso, pois seus pressupostos descaracterizam a formação docente, na acepção historicamente conquistada.
} 
Proclamação da República do Brasil, a escola foi delineando e consolidando seu papel de instituição especializada em promover/garantir o acesso das novas gerações à cultura letrada, aspecto que passa, essencialmente, pela alfabetização inicial e que se constitui o "principal índice de medida e testagem da eficiência da educação escolar" (Mortatti, 2008, p. 93).

Ao longo do tempo, propostas são feitas, métodos aparecem como salvadores e políticas públicas são adotadas, sempre acompanhados de discursos sobre a urgência em se resolver o problema da alfabetização e, no entanto, esta segue seu curso com índices que mostram uma reação lenta. Reação que evidencia avanços, sem dúvidas, mas que está longe da ambição, especialmente, de gestores guiados por uma concepção pragmática e imediatista, que veem em uma intervenção pontual (curso de curta duração, material, método, campanha) a possibilidade de retorno positivo rápido, com impacto nos números da alfabetização.

Hoje, conhecemos a complexidade desse processo, que envolve as dimensões pessoal e social, bem como conhecemos a complexidade da formação de professores e o frágil vínculo que ela tem com processos de inovação nas práticas.

Nos últimos 30 anos, a alfabetização viveu grande efervescência no Brasil. Na década de 1980, a entrada dos estudos sobre a psicogênese da língua escrita, desenvolvidos por Ferreiro e Teberosky (1985), trouxe novas teorias sobre a aprendizagem, causando um importante impacto nas práticas de ensino da leitura e da escrita, tidas como tradicionais e que não traziam bons resultados. Uma compreensão um tanto equivocada dessa teoria levou Soares (2004) a denominá-la "desinvenção da alfabetização", pois se supunha que a criança poderia avançar nas fases da psicogênese e chegar a construir a hipótese alfabética, sem um ensino sistemático e sem um método de alfabetização, apenas convivendo com diferentes materiais escritos.

Assim, essa concepção começou a ser criticada e revista. Passamos a ver a necessidade de se alfabetizar com o uso de diferentes métodos e metodologias e, sobretudo, de defender o ensino organizado do sistema de escrita alfabética, bem como o ensino das práticas de leitura e produção de textos. Essa concepção, baseada em vários estudos e pesquisas, passou a ser conhecida, entre nós, como aquela segundo a qual se deve alfabetizar letrando (Soares, 2004). Isso significa que, para além do domínio do sistema de escrita (alfabetização), a criança necessita desenvolver práticas de leitura e escrita de textos diversos, adequados a diferentes contextos (letramento). O processo de alfabetização é complexo e a aprendizagem inicial da língua escrita possui três facetas:

[...] a faceta linguística da língua escrita - representação visual da cadeia sonora da fala [...]; a faceta interativa da língua escrita - a língua escrita como veículo de interação entre pessoas, de expressão e compreensão de mensagens; a faceta sociocultural da língua escrita - os usos, funções e valores atribuídos à escrita em contextos socioculturais, estas duas últimas facetas consideradas [...] como letramento. (Soares, 2016, p. 28).

Essa complexidade tem permeado as lutas e os debates sobre alfabetização no Brasil, que, historicamente, se defronta com índices que pouco avançam e 
que muito preocupam. Em termos de proposições educacionais, destacamos as metas relativas à alfabetização, contidas no Plano Nacional de Educação (PNE 2014), a partir de sua publicação. O Plano lista dez diretrizes, sendo a primeira delas: "Art. $2^{\circ}$ [...] I. erradicação do analfabetismo" (Brasil. Lei nº 13.005, 2014).

Essa breve síntese pontua alguns desafios dos alfabetizadores e as principais influências intelectuais e legais que circulam no campo da alfabetização brasileira e que permeiam a proposta do Pnaic de que "estar alfabetizado significa ser capaz de interagir por meio de textos escritos em diferentes situações. Significa ler e produzir textos para atender a diferentes propósitos" (Brasil. MEC, 2012a, p. 17).

\section{O curso de formação}

Assistimos no Brasil, nas últimas décadas, à implantação pelo MEC de políticas públicas de formação continuada de professores, em atendimento a uma das metas do PNE 2014-2024. Entre essas metas, destacam-se iniciativas relacionadas à formação de alfabetizadores, a exemplo do Programa de Formação de Professores Alfabetizadores - Profa (2000); do Pró-Letramento (2005) e, mais recentemente, em 2012, do Pnaic.

Como política indutiva, o Pnaic foi instituído pela Portaria MEC nº 867, de 4 de julho de 2012. Apresentou-se como um programa de formação continuada de professores alfabetizadores, com vistas a garantir que todos os estudantes dos sistemas públicos de ensino se alfabetizassem em Língua Portuguesa e em Matemática até o final do $3^{\circ}$ ano do ensino fundamental. Para o alcance dessa meta, as ações do Pnaic compreendiam os eixos: formação continuada de professores alfabetizadores; materiais didáticos; literatura e tecnologias educacionais; avaliação; gestão, controle e mobilização social (Brasil. MEC, 2012b).

O diferencial do Pnaic em relação às políticas públicas de formação anteriores foi o de se propor universal, ou seja, proporcionar formação para todos os professores que atuavam nos três primeiros anos do ciclo básico, em salas multisseriadas ou multifases do Brasil, nos mais de 5 mil municípios, envolvendo mais de 300 mil professores alfabetizadores. Os objetivos do Pnaic são:

Art. $5^{\circ}[\ldots]$

I - garantir que todos os estudantes dos sistemas públicos de ensino estejam alfabetizados, em Língua Portuguesa e em Matemática, até o final do $3^{\circ}$ ano do ensino fundamental;

II - reduzir a distorção idade-série na Educação Básica;

III - melhorar o Índice de Desenvolvimento da Educação Básica (IDEB);

IV - contribuir para o aperfeiçoamento da formação dos professores alfabetizadores;

V - construir propostas para a definição dos direitos de aprendizagem e desenvolvimento das crianças nos três primeiros anos do ensino fundamental. (Brasil. MEC, 2012b, p. 23). 
O material do Pnaic sugere os princípios gerais da formação continuada, a saber: a prática da reflexividade; a mobilização dos saberes docentes; a constituição da identidade profissional; a socialização; e a colaboração (Brasil. MEC, 2012a). Esses princípios evidenciam uma concepção de formação na qual o professor é visto como sujeito ativo, que irá interagir com ferramentas conceituais e práticas de sala de aula, num movimento de alternância teoria/prática. Desse modo, há um respeito pelos saberes já construídos pelos professores, sem deixar de refletir sobre a possibilidade de repensar e ampliar tais saberes. Essa opção ajuda na constituição positiva da identidade profissional coletiva, com ênfase nos aspectos sociais da profissão e em seus relacionamentos, como também no despertar para continuar a aprender.

O MEC atribuiu às universidades públicas o papel de gerir e coordenar o programa de formação continuada, além de produzirem todo o material teóricodidático utilizado nos três anos de formação. Em Mato Grosso, a coordenação do Pnaic ficou ao encargo da Universidade Federal de Mato Grosso (UFMT), campus universitário de Rondonópolis. A formação está sintetizada nos Quadros 1 e 2, que apresentam, respectivamente, a organização e a metodologia da formação.

\section{Quadro 1 - Organização do Pnaic}

\begin{tabular}{|c|c|c|c|c|c|c|c|c|}
\hline \multirow[b]{2}{*}{$\frac{0}{4}$} & \multirow[b]{2}{*}{ 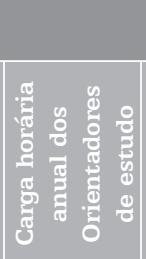 } & \multirow[b]{2}{*}{ 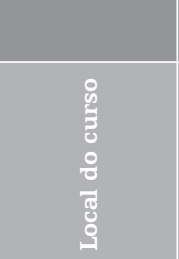 } & \multicolumn{2}{|c|}{ Equipe Gestora } & \multicolumn{3}{|c|}{ Participantes } & \multirow[b]{2}{*}{ 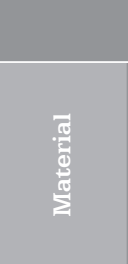 } \\
\hline & & & 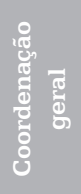 & 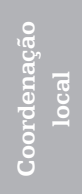 & 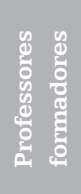 & 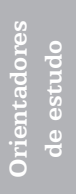 & 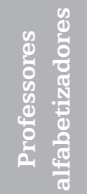 & \\
\hline 2013 & 200 & $\begin{array}{l}\text { Cuiabá } \\
\text { Rondonópolis } \\
\text { Sinop }\end{array}$ & 6 & 139 & 14 & 336 & 5.971 & $\begin{array}{c}32 \\
\text { Cadernos }\end{array}$ \\
\hline 2014 & 200 & Cuiabá & 8 & 139 & 28 & 323 & 6.124 & $\begin{array}{c}10 \\
\text { Cadernos } \\
+ \text { encarte } \\
\text { de jogos }\end{array}$ \\
\hline 2015 & 100 & Cuiabá & 10 & 139 & 9 & 322 & 5.957 & $\begin{array}{c}12 \\
\text { Cadernos }\end{array}$ \\
\hline
\end{tabular}

Fonte: Surveys realizadas anualmente em 2013, 2014 e 2015.

\section{Quadro 2 - Metodologia do Pnaic}

\begin{tabular}{|c|c|}
\hline Estratégias formativas & Atividades permanentes \\
\hline $\begin{array}{l}\text { - } \quad \text { Socialização de memórias; } \\
\text { - } \quad \text { Ańdeos em debate; } \\
\text { - } \text { - } \text { Análise de situações de salise de atividades de alunos; } \\
\text { - } \quad \text { Análise de relatos de rotinas, sequências didáticas, } \\
\text { - } \quad \text { Anojetos didáticos e planejamento de aula; } \\
\text { - Exposição dialogada; } \\
\text { - Elaboração de instrumentos de avaliação } \\
\text { - } \quad \text { Avaliação da formação. }\end{array}$ & $\begin{array}{l}\text { - Leitura deleite de textos literários } \\
\text { - } \quad \text { Tarefas para casa e retomada, em cada } \\
\text { encontro, com socialização das } \\
\text { atividades realizadas; } \\
\text { - } \text { Planejamento de atividades a serem } \\
\text { realizadas com os professores } \\
\text { alfabetizadores; } \\
\text { Estudo dirigido de texto, para } \\
\text { aprofundamento de saberes sobre os } \\
\text { conteúdos e estratégias didáticas. }\end{array}$ \\
\hline
\end{tabular}

Fonte: Surveys realizadas anualmente em 2013, 2014 e 2015. 


\section{Procedimentos metodológicos}

Este estudo se organiza a partir de pesquisas tipo survey realizadas em 2013, 2014 e 2015, tendo como sujeitos de interesse os participantes do perfil OE do Pnaic que responderam a três perguntas abertas: 1) Este curso contribuiu com sua formação? Por quê?; 2) Este curso causou algum impacto na sua prática? Qual?; e 3) Quais foram as principais mudanças observadas nas práticas dos seus professores cursistas? Obtivemos, ao longo dos anos citados, 321, 242 e 246 respostas, respectivamente.

Utilizamos a análise de conteúdo por categorização, que, segundo Bardin (2002), é desenvolvida pela pré-análise, pela exploração do material e pelo tratamento dos resultados. Na análise de conteúdo, as categorias são classes que reúnem um grupo de elementos em razão de características identificadas como comuns, facilitando uma esquematização e relacionando significações que ajudaram a responder à questão da pesquisa, garantindo critérios de objetividade fundamentais em um trabalho científico.

Inicialmente, foram analisados os temas mais recorrentes nas respostas por meio de nuvens de palavras, sobre contribuições, impactos e mudanças. O processo considerou as palavras que mais apareceram. Posteriormente, as respostas foram categorizadas em fragmentos de fala com significados, subcategorias e posteriormente em categorias explicativas dos dados.

\section{Delineando uma primeira análise}

Sobre contribuições, as palavras mais utilizadas pelos OE evidenciam, na Figura 1, a prevalência de respostas positivas ao longo dos anos. O tamanho da letra na imagem indica sua importância, destacando-se, desse modo, as palavras "sim" e "muito". Há ainda no rol das respostas positivas as palavras: "contribuiu", "com certeza", "certamente", "extremamente", entre outras.

Isso reforça a importância da continuidade da formação e, portanto, do investimento em políticas de longo prazo, tendo em vista a complexidade do processo de construção do conhecimento em rede, do processo de alfabetização e a necessidade de envolvimento dos atores sociais e educacionais, a fim de que se possa romper com as culturas escolares aprendidas em contexto (Viñao, 2007).

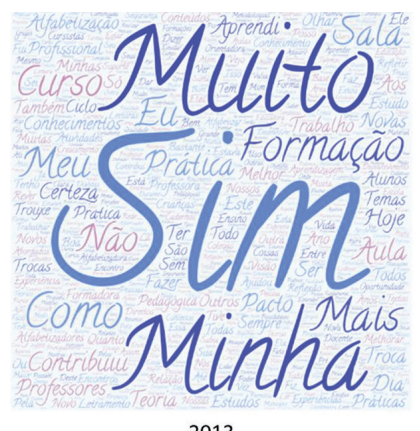

2013

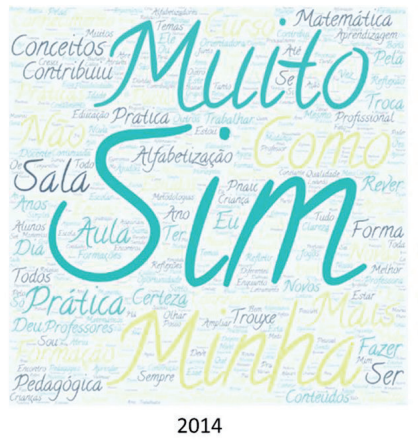

2014

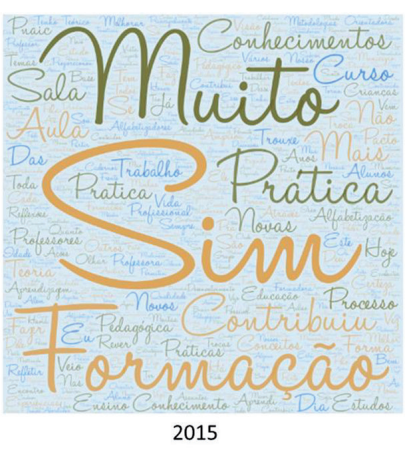

2015

Figura 1 - Contribuições

Fonte. Surveys realizadas anualmente em 2013, 2014 e 2015 
Sobre impactos, foram geradas as representações dispostas na Figura 2. Novamente aparecem em destaque respostas positivas marcadas pela palavra "sim", acrescida da palavra "muito". Várias respostas apresentavam "certamente", "com certeza", "foram muitas", todas com conotação positiva. A palavra "minha", também bastante utilizada, conforme mostram as Figuras 1 e 2, dispensa comentários na medida em que as duas perguntas relacionadas a contribuições e a impactos tematizavam a própria formação e prática dos respondentes.

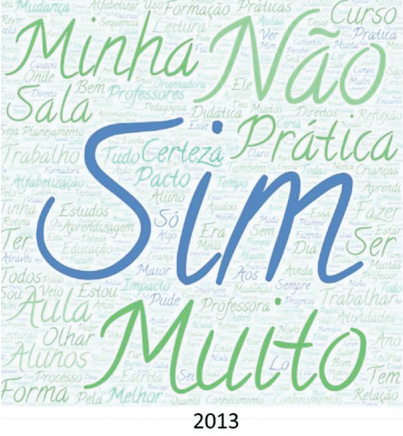

2013

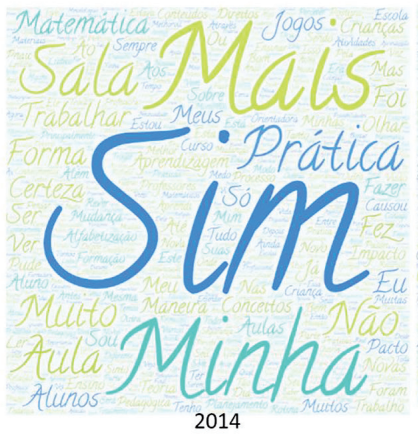

2014

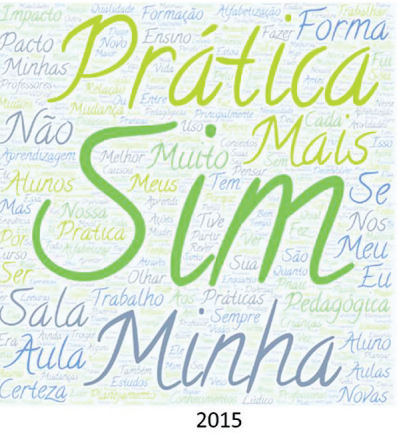

2015

Figura 2 - Impactos

Fonte: Surveys realizadas anualmente em 2013, 2014 e 2015.

Sobre mudanças, gerou-se a Figura 3, que se apresenta mais multifacetada. Como se tratava de apontar mudanças percebidas nas práticas dos alfabetizadores, ${ }^{2}$ várias palavras foram destaque, como "aulas", "alunos", "planejamento", "leitura", "deleite", "sequência", "sala", "aprendizagem", "jogos", "prática", "trabalho", "forma" e "uso".

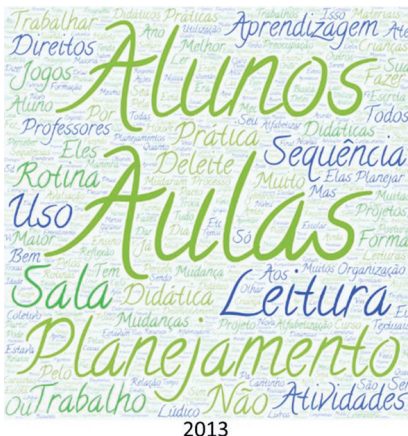

2013
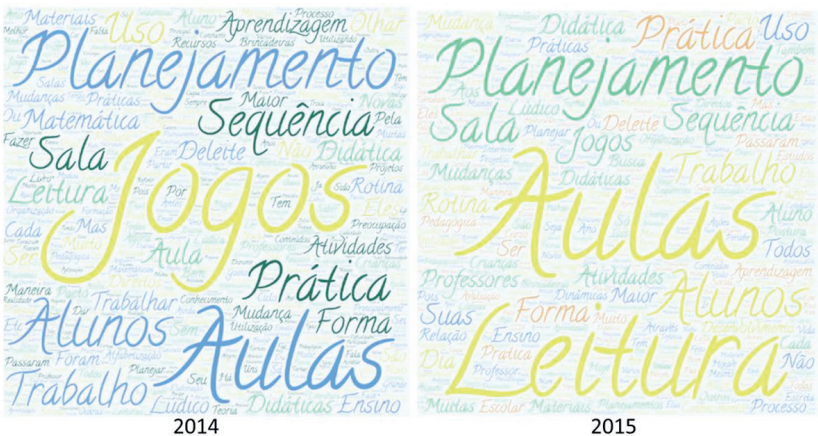

2015

Figura 3 - Mudanças

Fonte: Surveys realizadas anualmente em 2013, 2014 e 2015.

Como complementação da análise, as respostas foram categorizadas em fragmentos de fala com significados, subcategorias e depois em categorias explicativas dos dados, em que se evidencia a percepção dos OE sobre as contribuições, os impactos e as mudanças em suas práticas.

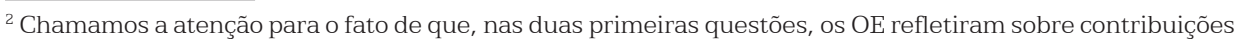
e impactos relativos a eles mesmos e suas práticas. Na terceira questão, eles se voltaram para os professores cursistas, mencionando mudanças observadas nas práticas desses alfabetizadores, para os quais ministravam o curso.
} 


\section{O que dizem os orientadores de estudo}

Na segunda análise, aplicamos o processo de categorização das respostas sobre contribuições, impactos e mudanças. O processo revelou seis categorias que explicam a percepção dos OE ao longo dos três anos pesquisados: 1) Objetivos do Pacto; 2) Objetivos dos Professores; 3) o Profissional; 4) Preparação do Professor; 5) Relacionamento com o Outro; e 6) Atividades de Sala de Aula.

Na categoria Objetivos do Pacto, os respondentes destacaram a importância da educação, da formação continuada e do investimento na alfabetização. As palavras "formação(ões)" e "alfabetização(ar)(dores)" foram as mais utilizadas, como nos exemplos de fragmentos de falas:

A contribuição do curso para minha formação foi imensa, pois com o PACTO ampliei meus conhecimentos e hoje me sinto mais preparada para atuar na alfabetização das crianças. (OE 23, 2013)

Sim. Historicamente a educação necessitava de uma reorganização das práticas pedagógicas, especialmente, estabelecer um parâmetro para a alfabetização da criança, qual a idade que essa criança deve estar lendo. O Pacto estabeleceu este tempo e fomentou a reconstrução da minha prática pedagógica. (OE 97, 2014)

O compromisso de alfabetizar todas as crianças teve prioridade no decorrer do processo formativo aliado a práticas pedagógicas significativas. (OE 123, 2015)

Tem-se uma percepção favorável e alinhada aos objetivos previstos na portaria (Brasil. MEC, 2012b), em termos de ações para alfabetizar as crianças até o final do $3^{\circ}$ ano do ensino fundamental, proporcionando o direito de aprendizagem e desenvolvimento delas, e reduzindo a distorção idade-série na educação básica. Entende-se isso como metas a serem buscadas, a partir do contínuo aperfeiçoamento da formação dos professores alfabetizadores.

A categoria Objetivos dos Professores está associada às percepções sobre a contínua busca por conhecimento, aprendizagem, planejamento das atividades e até mesmo a disponibilidade de mudança em suas práticas a partir de reflexões. Não é à toa que as palavras mais utilizadas nessa categoria são "conhecimento" e "aprendizado(gem)", revelando a preocupação de se sentir preparado para desenvolver uma prática contextualizada, atenta à cultura e aos saberes do professor/ aluno e, sobretudo, exitosa. Alguns exemplos dessa categoria informam essas percepções:

Sim. Adquiri conhecimentos teóricos, assim como, práticos, que me instrumentalizaram e contribuíram para que pudesse desenvolver meu trabalho com as alfabetizadoras. (OE 32, 2013)

Certamente, pois ampliando meus conhecimentos, adquiri também mais segurança e experiência, o que certamente tem contribuído para que minha prática seja mais articulada e organizada. (OE 174, 2014)

Sim. As temáticas e reflexões possibilitaram retomar algumas concepções e o replanejamento de algumas ações na alfabetização. (OE 21, 2015)

A categoria o Profissional se associa, fundamentalmente, às percepções ligadas, por um lado, à função de professor e, neste momento, orientador de seus 
colegas, demandas e saberes exigidos e, por outro lado, às questões de formação, identidade profissional e carreira. A palavra mais utilizada foi "professor(a)", ficando em segundo lugar "alfabetizador(a)". Alguns exemplos:

Sim. Sou também professora alfabetizadora neste ano trabalhei com 19 alunos do $1^{\circ}$ ano. Desprender do ritmo antigo não é fácil, porém não é impossível. Consegui sucesso e com a graça de DEUS recebi no curso o privilégio de motivar também os professores alfabetizadores. (OE 111, 2013)

Sim, pois além dos conhecimentos adquiridos, tive a oportunidade de iniciar uma nova etapa na minha vida profissional, que é a carreira de formadora de professores. (OE 129, 2014)

Motivação e confiança enquanto profissional, participação efetiva nas formações e flexibilização no planejamento. (OE 15, 2015)

Na categoria Preparação do Professor, destaca-se a palavra "prática", ficando em segundo lugar a palavra "pedagógica(o)". Tal categoria sistematiza as percepções dos OE em relação à teoria, à prática e ao conteúdo da alfabetização, apropriação de novos conceitos e modos de ensinar, bem como formas de planejamento, elementos que trazem segurança para o exercício da docência. Há, claramente, uma receptividade dos professores à sua própria aprendizagem, aspecto que estudos mostram possuir correlação positiva com os resultados de aprendizagem dos alunos.

Planejamento prévio, diagnóstico de seus alunos, criatividade, reflexão teoria e prática, persistência diante das dificuldades, pesquisa do que não sei e disposição para procurar saber fazer! (OE, 51, 2013)

Sim. Porque já possuímos a prática e o domínio de muitas das temáticas trabalhadas, só que dessa vez a formação trabalhou teoria e prática ao mesmo tempo, nos levando a uma maior reflexão e revisão da nossa prática em sala de aula [...]. (OE 57, 2014)

Percebi que os professores passaram a valorizar mais a escrita e produções espontâneas dos alunos, organizar melhor o trabalho pedagógico, valorizar as práticas de leitura e escrita das crianças. Muitos que não usavam as ferramentas das tecnologias passaram a utilizar e aprenderam a produzir seus materiais para apresentações em multimídias. (OE 19, 2015)

Na categoria Relacionamento com o Outro, preponderam as palavras "aula", "aluno" e "criança". Essa categoria aponta em direção às contribuições, aos impactos e às mudanças que favoreceram um "olhar" diferente a esse outro, quase sempre, o aluno, mas também aos pares, colegas, coordenadores e diretores.

Percebo que os professores com os quais trabalhei estão mais motivados e solidários uns com os outros. Ficaram mais preocupados com planejamento diário das aulas e da organização do trabalho pedagógico. (OE 33, 2013)

Porque me proporcionou maiores conhecimentos em matemática e também me possibilitou a participar de perto dos trabalhos pedagógicos realizados pelos Alfabetizadores e alunos, bem como vivenciar as mudanças ocorridas em suas práticas. (OE 70, 2014)

Percebi a mudança de postura dos professores ao se relacionarem com as crianças; buscaram novas estratégias e metodologias, além de demonstrarem mais motivadas nas suas ações. (OE 107, 2015) 
A categoria Atividades de Sala de Aula se expressa, em especial, pelas palavras "trabalho" e "trabalhar". Nota-se a preocupação com os conteúdos e com as novas e diferentes formas de se encaminhar as atividades em classe, visando ao ensinoaprendizagem das crianças. A categoria demonstra que os professores e orientadores receberam com entusiasmo e acataram as diferentes maneiras de trabalho, sendo que as atividades de sequência didática, leitura e jogos são as que mais se destacam.

Eles passaram a trabalhar mais com leituras de histórias em suas diversas formas e o trabalho com sequência didática e os gêneros textuais. (OE 61, 2013)

Causou grande impacto. A transformação na maneira de ministrar as aulas. Com a diversidade de atividades e jogos apresentados as aulas ficaram mais lúdicas e prazerosas. (OE 152, 2014)

Adotaram as caixas de jogos, cantinho da leitura, leitura deleite e principalmente mais conhecimento sobre como se aprende e ensina. (OE 62, 2015)

Após a exploração das categorias encontradas, é possível fazer inferências, situando-as no ciclo de política, notadamente, no contexto da prática e no contexto dos resultados (efeitos). Nota-se que o Pnaic, enquanto política pública de formação de alfabetizadores, causou, na perspectiva dos OE, variados efeitos de primeira ordem, entendidos como aqueles que se referem a mudanças na prática ou na estrutura, evidentes em lugares específicos ou no sistema como um todo.

Outra possível inferência sobre as contribuições do curso, refere-se à possibilidade de alinhar os Objetivos do Pacto aos Objetivos dos Professores, propiciando conhecimento, reflexão e aprendizagem, visando à melhoria do ensino.

A Preparação do Professor, por meio de práticas pedagógicas, conceitos, teorias, metodologias e conteúdos do Pnaic, proporcionou diversas Atividades de Sala de Aula, considerando uma aproximação entre o outro (aluno, criança, pares) e o profissional da educação (professor, alfabetizador), resultando em percepções favoráveis sobre as contribuições para a prática em termos de experiências, trocas, aprendizagens e revisão dessa prática. Algumas respostas dão essa dimensão:

Sim, muito! O aprofundamento teórico-metodológico me deu segurança tanto para orientar como para desenvolver a prática na sala de aula. (OE 7, 2013)

Sim. Porque já possuímos a prática e o domínio de muitas das temáticas trabalhadas, só que dessa vez a formação trabalhou teoria e prática ao mesmo tempo nos levando a uma maior reflexão e revisão da nossa prática em sala de aula e um novo olhar para o nosso aluno no que diz respeito aos direitos de aprendizagem. (OE 55, 2014)

Contribuiu, pois aprimorou meus conhecimentos acerca da alfabetização e ampliou o uso de metodologias inovadoras que apresentaram excelentes resultados. (OE 27,2015$)$

A participação no curso de formação provocou impactos nas práticas pedagógicas, a partir dos Objetivos do Pacto, com a intensificação do planejamento e da didática na Preparação do Professor e na relação com o outro em termos de seus direitos de aprendizagem. As Atividades de Sala de Aula sofreram impacto pela 
utilização de sequências didáticas, jogos e leituras, que encaminhavam para a reflexão teórico-prática; além disso, o Profissional passou a se ver com mais competência e segurança. Tudo isso resulta em percepções favoráveis dos OE sobre esses impactos, conforme atestam as falas:

Sem dúvida. Estive como formadora neste Pnaic, mas sou professora e adoro alfabetizar, por isso incorporei em minha prática uma rotina voltada para os Quadros de Direitos de Aprendizagem, já os conhecia do Pró-letramento, mas tinha insegurança e não fazia uso deles. As definições de sequência didática e projetos didáticos também foram de grande valia para minha prática, bem como o trabalho com as obras complementares e outros materiais enviados pelo MEC. (OE 10, 2013)

Muito impacto, hoje sei diagnosticar, desenvolver projetos e sequências didáticas e avaliar, bem como classificar através da psicogênese da escrita. (OE 92, 2014)

Sim! O de rever, analisar as minhas atitudes como educadora, o meu crescimento profissional, aperfeiçoamento com os meios tecnológicos, enfim, o Pacto para mim, foi uma $2^{a}$ licenciatura. (OE 214, 2015)

Segundo os OE, a participação no curso de formação proporcionou mudanças nas práticas pedagógicas dos alfabetizadores, indo ao encontro dos Objetivos do Pacto, com um professor mais consciente da importância do planejamento, dos direitos de aprendizagem e das novas formas de avaliação. A Preparação do Professor aparece muito valorizada e muda, também, sua relação com o outro, especialmente o aluno, que é visto com necessidades e saberes. As Atividades de Sala de Aula passaram por mudanças qualitativas, expressas por um melhor uso do tempo, utilização de diferentes metodologias, incremento da leitura deleite, além do uso de jogos e da valorização do lúdico, e, como resultado, o Profissional sente-se mais seguro e preparado, aspectos que apontam percepções favoráveis dos OE sobre as mudanças trazidas com o curso:

Sim. Por meio desse curso eu pude perceber que algo poderia ser diferente no meu dia a dia de sala de aula, passei a organizar e dividir melhor meu tempo de modo a atender as diversas áreas do conhecimento. Ampliei mais as possibilidades de leituras com as crianças mediante os materiais recebidos. Isso foi percebido no resultado final dos alunos que já conseguiam ler, produzir pequenas frases e textos. (OE 28, 2013)

As principais mudanças foram: organização dos planejamentos, utilização de projetos e sequências didáticas, refletir sobre os direitos de aprendizagem, etc. (OE 54, 2014)

Sempre há mudanças qualitativas quando relacionamos a teoria e a prática educacional. Penso que o que causou impacto foi a questão dos temas abordados no caderno 02 que trata da importância das brincadeiras e da ludicidade no ensino e aprendizado de crianças de qualquer idade. (OE 157, 2015)

Nossos achados ressaltam percepções favoráveis do grupo de professores que participou do Pnaic de Mato Grosso. Como programa de alcance nacional, o Pnaic foi e continua sendo estudado de diversos ângulos e com base em diferentes fundamentos teóricos. Nesse sentido, muitos estudos apresentam avanços e outros tantos mostram limites. Um dos limites, previsto inclusive na Portaria MEC $n^{\circ}$ 867/2012, foi o atrelamento automático do curso de formação à Avaliação Nacional de Alfabetização (ANA), denotando uma visão utilitarista e reducionista de formação de professores e de aprendizagem dos alunos. 


\section{Considerações finais}

Iniciamos este texto com o objetivo de explorar as percepções dos OE acerca das contribuições, dos impactos e das mudanças nas práticas pedagógicas, após terem participado da formação do Pnaic, em Mato Grosso, entre 2013 e 2015.

Foram sistematizadas seis categorias analíticas que evidenciaram percepções favoráveis dos OE em relação à formação continuada de alfabetizadores, sinalizando aspectos concernentes às contribuições, aos impactos e às mudanças nas práticas pedagógicas, aliados aos princípios formativos, aos objetivos e ao processo de formação continuada realizada pelo Pnaic.

Considerando a visão de conjunto de políticas, e tendo em mente que o processo político é multifacetado e dialético, o que requer articulação entre perspectivas "macro" e "micro", reforçamos a ideia de um ciclo, utilizando as categorias deste estudo e os contextos indicados por Mainardes (2006). A Figura 4 inter-relaciona os três contextos do ciclo de políticas com as percepções de profissionais diretamente envolvidos com a adoção de uma política de formação, que não enfrentam os textos políticos como leitores ingênuos, pois trazem para a interpretação suas experiências, suas histórias e seus saberes. As categorias se ligam a efeitos percebidos pelos OE (contribuições, impactos e mudanças) e que levam a um novo ciclo de reflexão e ação em termos de objetivos do Pacto, objetivo dos professores, o profissional, a preparação do professor, a relação com o outro e as atividades de sala de aula. Vislumbramos um movimento de mútua alimentação, macro (proposição pelo MEC), meso (formação pela universidade), micro (formação nos municípios), que pode fazer o caminho inverso (micro, meso, macro), caracterizando os ciclos de políticas.

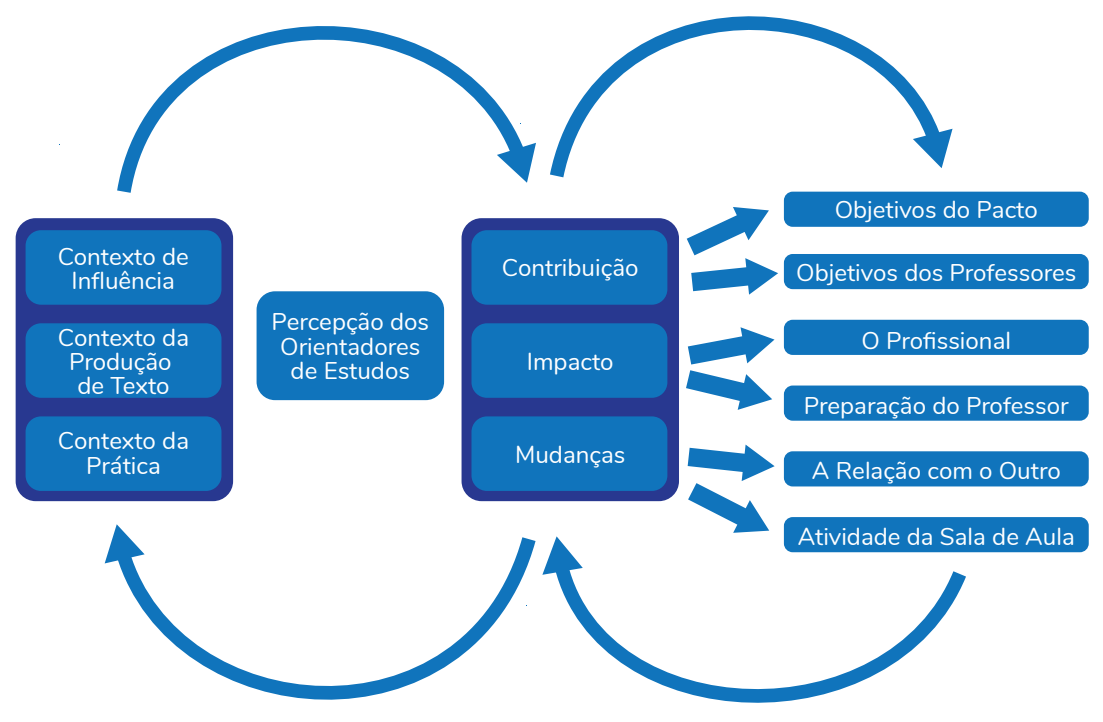

Figura 4 - Categorias e sua relação com o ciclo de políticas

Fonte: Elaboração própria. 
Por fim, os resultados desta pesquisa, materializados em apontamentos sobre os "resultados/efeitos de primeira ordem" (Mainardes, 2018), sugerem avanço na compreensão do complexo processo de alfabetização (Soares, 2016). Recomendam, ainda, que as políticas educacionais têm muito a ganhar escutando os sujeitos nelas envolvidos, aqueles que são determinantes em qualquer mudança ou reforma, pois essa escuta poderá direcionar a correção de rumos e o aprofundamento de ações.

\section{Referências bibliográficas}

BALL, S. J.; BOWE, R. Subject departments and the "implementation" of National Curriculum policy: an overview of the issues. Journal of Curriculum Studies, [London], v. 24, n. 2, p. 97-115, Mar. 1992.

BARDIN, L. Análise de conteúdo. Lisboa: Edições 70, 2002.

BRASIL. Lei no 11.738, de 16 de julho de 2008. Regulamenta a alínea "e" do inciso III do caput do art. 60 do Ato das Disposições Constitucionais Transitórias, para instituir o piso salarial profissional nacional para os profissionais do magistério público da educação básica. Diário Oficial da União, Brasília, DF, 17 jul. 2008. Seção 1, p. 1.

BRASIL. Lei $\mathrm{n}^{\circ}$ 12.796, de 4 de abril de 2013. Altera a Lei no 9.394, de 20 de dezembro de 1996, que estabelece as diretrizes e bases da educação nacional, para dispor sobre a formação dos profissionais da educação e dar outras providências. Diário Oficial da União, Brasília, DF, 5 abr. 2013. Seção 1, p. 1.

BRASIL. Lei no 13.005, de 25 de julho de 2014. Aprova o Plano Nacional de Educação - PNE e dá outras providências. Diário Oficial da União, Brasília, DF, 26 jul. 2014. Seção 1, p. 1.

BRASIL. Conselho Nacional de Educação (CNE). Conselho Pleno (CP). Resolução $\mathrm{n}^{\circ} 2$, de $1^{\circ}$ de julho de 2015. Define as Diretrizes Curriculares Nacionais para a formação inicial em nível superior (cursos de licenciatura, cursos de formação pedagógica para graduados e cursos de segunda licenciatura) e para a formação continuada. Diário Oficial da União, Brasília, DF, 2 jul. 2015. Seção 1, p. 8.

BRASIL. Conselho Nacional de Educação (CNE). Conselho Pleno (CP). Resolução $\mathrm{n}^{\circ}$ 2, de 20 de dezembro de 2019. Define as Diretrizes Curriculares Nacionais para a Formação Inicial de Professores para a Educação Básica e institui a Base Nacional Comum para a Formação Inicial de Professores da Educação Básica (BNC-Formação). Diário Oficial da União, Brasília, DF, 23 dez. 2019. Seção 1, p. 115. 
BRASIL. Ministério da Educação (MEC). Pacto Nacional pela Alfabetização na Idade Certa (Pnaic): o Brasil do futuro com o começo que ele merece. Brasília: MEC, 2012a.

BRASIL. Ministério da Educação (MEC). Portaria no 867, de 4 de julho de 2012. Institui o Pacto Nacional pela Alfabetização na Idade Certa e as ações do Pacto e define suas diretrizes gerais. Diário Oficial da União, Brasília, DF, 5 jul. 2012b. Seção 1, p. 22. Disponível em: < https://www.abmes.org.br/arquivos/legislacoes/Port-867-2012-0704.pdf > . Acesso em: 30 de set 2020.

CANÁRIO, R. O que é a escola? Um "olhar" sociológico. Porto: Porto Editora, 2005.

FERREIRO, E.; TEBEROSKI, A. Psicogênese da língua escrita. Porto Alegre: Artes Médicas, 1985.

GATTI, B. A.; BARRETO, E. S. S.; ANDRÉ, M. E. D. A. Políticas docentes no Brasil: um estado da arte. Brasília: Unesco; MEC, 2011.

MAINARDES, J. A abordagem do ciclo de políticas e suas contribuições para a análise da trajetória de políticas educacionais. Atos de Pesquisa em Educação, Blumenau, v. 1, n. 2, p. 94-105, maio/ago. 2006.

MAINARDES, J. A abordagem do ciclo de políticas: explorando alguns desafios da sua utilização no campo da política educacional. Jornal de Políticas Educacionais, Curitiba, v. 12, n. 16, p. 1-19, ago. 2018.

MORTATTI, M. R. L. A "querela dos métodos" de alfabetização no Brasil: contribuições para metodizar o debate. Acolhendo a Alfabetização nos Países de Língua Portuguesa, São Paulo, v. 3, n. 5, p. 91-114, 2008.

NÓVOA, A. Professores: imagens do futuro presente. Educa: Lisboa, 2009.

SOARES, M. Letramento e alfabetização: as muitas facetas. Revista Brasileira de Educação, Rio de Janeiro, n. 25, p. 5-17, jan./abr. 2004.

SOARES, M. Alfabetização: a questão dos métodos. São Paulo: Contexto, 2016.

VIÑAO, A. Sistemas educativos, culturas escolares e reformas. Mangualde, Portugal: Edições Pedago, 2007. 
Cancionila Janzkovski Cardoso, doutora em Educação pela Universidade Federal de Minas Gerais, com estágio no Institut National de Recherche Pédagogique (Paris) e pós-doutorado pela Universidade Federal do Paraná (UFPR), é professora associada da Universidade Federal de Mato Grosso (UFMT). Coordena o grupo de pesquisa Alfabetização e Letramento Escolar (Alfale), cadastrado no CNPq.

kjc@terra.com.br

André Luís Janzkovski Cardoso, doutor em Administração pela Pontifícia Universidade Católica do Paraná (PUC-PR), é professor de mestrado em Gestão e Tecnologia Ambiental e de Administração da Universidade Federal de Rondonópolis (UFR).

cardoso9778@gmail.com

Recebido em 31 de março de 2020

Aprovado em 29 de maio de 2020 